\title{
Outcome of 200 patients after an extracardiac Fontan procedure
}

\author{
Soo-Jin Kim, MD, PhD, ${ }^{a}$ Woong-Han Kim, MD, PhD, ${ }^{c}$ Hong-Gook Lim, MD, ${ }^{b}$ and Jae-Young Lee, MD ${ }^{\mathrm{a}}$
}

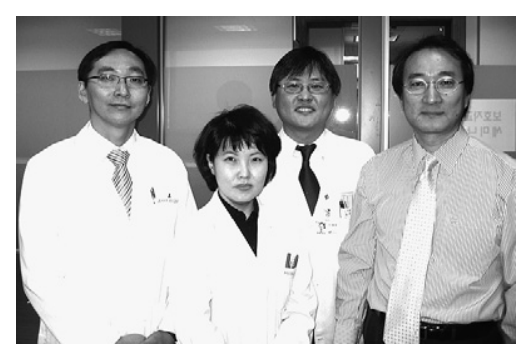

Lim, Kim SJ, Lee, Kim WH (left to right)
Objectives: Despite the known advantages of the extracardiac conduit Fontan procedure, the long-term outcomes related to the longevity of the conduit and anticoagulation therapy have not been determined. The purpose of this study was to evaluate the outcome of hospital survivors with an extracardiac Fontan circulation.

Methods and Results: Between 1996 and 2006, 200 patients had the extracardiac conduit Fontan operation. The median age at operation was 3.4 years. Most patients $(89.5 \%)$ underwent a bidirectional cavopulmonary shunt. Fenestration was required in 85 patients. Overall, the 10 -year survival was $92.4 \% \pm 2.1 \%$. Multivariate analysis identified severe infection during the early postoperative period and a high pulmonary arterial pressure during the preoperative period as independent risk factors for patient mortality. The Kaplan-Meier estimate for freedom from reoperation was $82.4 \% \pm$ $4.1 \%$ at 10 years. Arrhythmia occurred in 32 patients after the Fontan operation; freedom from arrhythmia was $85.1 \% \pm 4.4 \%$ at 10 years. The risk factors for arrhythmia were the heterotaxy syndrome, follow-up duration, and age at Fontan operation. Freedom from thromboembolism at 10 years was $92.9 \% \pm 1.9 \%$. Among all of the patients, $95.2 \%$ were classified in New York Heart Association class I.

Conclusions: The results of this study showed that during 10 years of follow-up, the overall survival and the functional status of the survivors after an extracardiac Fontan procedure were satisfactory. We might infer that fenestration provided benefit inasmuch as the high-risk Fontan patients fenestrated had similar outcomes to those not fenestrated, who were presumably low risk. The incidence of late death, reoperation, obstruction of the cavopulmonary pathway, arrhythmias, and thromboembolism was low.

From the Departments of Pediatric Cardiolo$\mathrm{gy}^{\mathrm{a}}$ and Cardiothoracic Surgery, ${ }^{\mathrm{b}}$ Sejong General Hospital, Sejong Heart Institute, Bucheon, Korea, and the Department of Thoracic and Cardiovascular Surgery, Seoul National University College of Medicine, Seoul National University Children's Hospital, ${ }^{\mathrm{c}}$ Seoul, Korea.

Received for publication Sept 26, 2007; revisions received Dec 18, 2007; accepted for publication Dec 27, 2007.

Address for reprints: Woong-Han Kim, MD, Department of Thoracic \& Cardiovascular Surgery, Clinical Research Institute, Seoul National University, College of Medicine, Seoul National University Children's Hospital, 28 Yongon-Dong, Jongno-Gu, Seoul, 110-744, Korea (E-mail: woonghan@snu. ac.kr).

J Thorac Cardiovasc Surg 2008;136:108-16 $0022-5223 / \$ 34.00$

Copyright $\odot 2008$ by The American Association for Thoracic Surgery

doi:10.1016/j.jtcvs.2007.12.032
$\mathrm{M}$ ost patients treated with single ventricle lesions ultimately undergo the Fontan procedure. The extracardiac conduit Fontan has several advantages including excellent hemodynamics and low rates of arrhythmia, as well as being a simple surgical technique. ${ }^{1,2}$ However, this procedure has potential disadvantages related to using an extracardiac tube, including the lack of growth potential, conduit stenosis resulting from intimal peel formation, an increased risk of thromboembolism, and the need for reoperation. Although many other modifications have been described in the medical literature, few large series have addressed the long-term outcome, in the current era, after undergoing an extracardiac Fontan modification. The use of fenestration has reduced the procedure-related morbidity and mortality in high-risk patients but has the disadvantages of desaturation and paradoxical embolism. The purpose of this study was to evaluate the midterm outcome of hospital survivors with extracardiac Fontan circulation and to determine the role of fenestration in high-risk patients.

\section{Methods}

\section{Patient Characteristics}

Clinical data obtained from the medical records of 200 patients who received an extracardiac Fontan operation at the Sejong General Hospital between August 1996 and August 2006 was reviewed. The records of these patients were reviewed for the operative and perioperative 


\section{Abbreviations and Acronyms \\ BCPS = bidirectional cavopulmonary shunt \\ PAP = pulmonary arterial pressure \\ $\mathrm{PLE}=$ protein-losing enteropathy \\ PVR = pulmonary vascular resistance \\ $\mathrm{SaO}_{2}=$ arterial oxygen saturation \\ $\mathrm{TPG}=$ transpulmonary gradient}

features, follow-up echocardiographic, Holter electrocardography, catheterization, and clinical data. These results were compared between a group with fenestration and a group without fenestration procedures. Table I shows the primary diagnoses for the 200 patients. Sixty-four $(32 \%)$ patients had a diagnosis of heterotaxy. The Sejong General Hospital Institutional Review Board reviewed and approved this study and individual consent was waived.

\section{Surgical Technique}

Among the 200 patients, 188 patients had received at least one operation before the bidirectional cavopulmonary shunt (BCPS) or the Fontan operation. The initial palliations were Blalock-Taussig shunt in $56(28.0 \%)$, pulmonary banding in $36(18.0 \%)$, coarctation of the aorta repair in 5, Norwood stage I in 4, atrial septectomy in 3, Damus-Kaye-Stansel procedure in 2, pulmonary artery angioplasty in 2, and interrupted aortic arch repair in 1.

All patients (89.5\%), except 21 who had a 1-stage Fontan operation, had a BCPS. Fenestration was required in 85 (42.5\%) patients. The pre-Fontan procedures were as follows: BCPS in $179(89.5 \%)$, atrial septectomy in 51, pulmonary artery angioplasty in 30 , atrioventricular valve repair in 9, Damus-Kaye-Stansel procedure in 4 , left ventricular outflow tract obstruction relief in 4, atriopulmonary Fontan in 3, total anomalous pulmonary venous return repair in 2, permanent pacemaker implantation in 2, aortic valve replacement in 1, atrioventricular valve replacement in 1 , coarctation of aorta repair in 1, and right ventricle exclusion in 1.

At Fontan, patients were operated on through a median sternotomy with mild hypothermia and cardiopulmonary bypass. If there was no planned concomitant intracardiac procedure, the procedure was basically performed with the heart beating. If we had to make an atrial septectomy, we transected the inferior vena cava and carried out atrial septectomy under temporary ventricular fibrillation. An expanded polytetrafluoroethylene tube conduit (Gore-Tex vascular graft; W. L. Gore \& Associates, Inc, Flagstaff, Ariz) was used throughout except for 20 patients; a Hemashield graft (Boston Scientific, Natick, Mass) was used in 18 patients, and a homograft in 2 . The mean diameter of the conduits used was $18.93 \pm 2.24 \mathrm{~mm}$ (range 14.0-24.0 mm) for the entire cohort. The fenestrations were made with a polytetrafluoroethylene tube graft (median $4 \mathrm{~mm}$, range $3.5-8 \mathrm{~mm}$ ). The decision to use fenestrations was made in the operating room after weaning the patient from cardiopulmonary bypass. The criteria for using fenestrations were (1) a pulmonary arterial pressure (PAP) greater than $18 \mathrm{~mm} \mathrm{Hg}$ or a transpulmonary gradient (TPG) greater than $10 \mathrm{~mm} \mathrm{Hg}$, or both, and (2) risk factors for a Fontan operation.

The combined procedures included the following: an atrial septectomy in 43 , pulmonary artery angioplasty in 22 , atrioventricular
TABLE 1. Primary diagnosis

\begin{tabular}{lc}
\hline \multicolumn{1}{c}{ Primary diagnosis } & No (\%) \\
\hline Isomerism & $64(32.0 \%)$ \\
Tricuspid atresia & $28(14.0 \%)$ \\
Congenitally corrected TGA & $18(9.0 \%)$ \\
CAVSD & $13(6.5 \%)$ \\
Mitral atresia & $11(5.5 \%)$ \\
Criss-cross & $10(5.0 \%)$ \\
DIRV & $9(4.5 \%)$ \\
Pulmonary atresia with IVS & $7(3.5 \%)$ \\
DILV & $6(3.0 \%)$ \\
HLHS & $4(2.0 \%)$ \\
Ebstein anomaly & $3(1.5 \%)$ \\
Other complex & $27(13.5 \%)$ \\
Total & $200(100 \%)$ \\
\hline
\end{tabular}

TGA, Transposition of the great arteries; CAVSD, complete atrioventricular septal defect; DIRV, double-inlet right ventricle; IVS, intact ventricular septum; DILV, double-inlet left ventricle; $H L H S$, hypoplastic left heart syndrome.

valve repair in 20 , left ventricular outflow tract obstruction relief in 4 , coronary sinus unroofing in 4 , permanent pacemaker implantation in 4 , right-sided maze in 3, isthmus cryoablation in 2, Damus-KayeStansel procedure in 2, aortic valvuloplasty in 2, total anomalous pulmonary venous return repair in 1 , cor triatriatum membrane resection in 1, ascending aorta reduction plasty in 1, and tricuspid valve exclusion in 1 .

\section{Statistical Analysis}

Statistical analyses were performed with SPSS version 11.0 software (SPSS, Inc, Chicago, Ill). All results were expressed as a mean \pm standard deviation. The differences between the two groups were assessed by the unpaired Student $t$ test, the $\chi^{2}$ test, or the Fisher exact test. Actuarial data were analyzed by the KaplanMeier formula. Differences between the groups were evaluated by a log-rank test. The follow-up status of patients was determined by retrospective review of hospital records or by telephone interviews.

\section{Results}

Among the 200 patients who underwent the extracardiac Fontan operation, 109 (54.5\%) were male and 91 (45.5\%) were female. The median age at the time of the Fontan operation was 3.4 years (range 16 months to 35.7 years). The interval between BCPS and Fontan completion was a median of 26.2 months (range 8.5-154.5 months). A fenestration was placed in $85(42.5 \%)$ patients. The annual rate of fenestration placement progressively decreased from $67 \%$ in 1997 to $17 \%$ in 2006. Preoperative catheterization data are detailed in Table 2. The preoperative PAP was significantly higher in the fenestration group than in the patients without fenestration $(13.3 \pm 3.2$ vs $11.7 \pm 3.1 \mathrm{~mm} \mathrm{Hg}$; $P=.001)$, as were the preoperative TPG $(5.34 \pm 2.00 \mathrm{vs}$ $4.50 \pm 1.70 \mathrm{~mm} \mathrm{Hg} ; P=.003)$ and the preoperative pulmonary vascular resistance $(\mathrm{PVR})(1.76 \pm 0.70$ vs 1.47 $\left.\pm 0.64 \mathrm{U} / \mathrm{m}^{2} ; P=.004\right)$. 
TABLE 2. Catheterization data before and after the Fontan operation

\begin{tabular}{|c|c|c|c|c|}
\hline Variable & Total $(n=200)$ & Fenestration $(\mathrm{n}=85)$ & No fenestration $(n=115)$ & $P$ value \\
\hline \multicolumn{5}{|l|}{ Preoperative } \\
\hline PAP $(\mathrm{mm} \mathrm{Hg})$ & $12.4 \pm 3.3$ & $13.3 \pm 3.2$ & $11.7 \pm 3.1$ & .001 \\
\hline VEDP $(\mathrm{mm} \mathrm{Hg})$ & $9.97 \pm 3.33$ & $10.15 \pm 3.78$ & $9.84 \pm 2.96$ & .524 \\
\hline $\mathrm{TPG}(\mathrm{mm} \mathrm{Hg})$ & $4.85 \pm 1.87$ & $5.34 \pm 2.00$ & $4.50 \pm 1.70$ & .003 \\
\hline $\operatorname{PVR}\left(\mathrm{U} / \mathrm{m}^{2}\right)$ & $1.60 \pm 0.68$ & $1.76 \pm 0.70$ & $1.47 \pm 0.64$ & .004 \\
\hline \multicolumn{5}{|l|}{ Last follow-up } \\
\hline PAP $(\mathrm{mm} \mathrm{Hg})$ & $14.0 \pm 3.6$ & $14.4 \pm 3.6$ & $13.7 \pm 3.7$ & .351 \\
\hline VEDP $(\mathrm{mm} \mathrm{Hg})$ & $10.9 \pm 3.8$ & $10.8 \pm 3.4$ & $11.0 \pm 4.1$ & .787 \\
\hline $\mathrm{TPG}(\mathrm{mm} \mathrm{Hg})$ & $4.81 \pm 1.99$ & $4.86 \pm 2.07$ & $4.76 \pm 1.92$ & .829 \\
\hline $\operatorname{PVR}\left(\mathrm{U} / \mathrm{m}^{2}\right)$ & $1.61 \pm 0.84$ & $1.78 \pm 0.93$ & $1.46 \pm 0.72$ & .100 \\
\hline $\mathrm{SaO}_{2}(\%)$ & $91.8 \pm 4.6$ & $90.8 \pm 4.4$ & $92.6 \pm 4.6$ & .044 \\
\hline $0 s\left(\mathrm{~L} \cdot \min ^{-1} \cdot \mathrm{m}^{-2}\right)$ & $3.90 \pm 1.22$ & $3.84 \pm 1.37$ & $3.96 \pm 1.07$ & .665 \\
\hline
\end{tabular}

$P A P$, Pulmonary artery pressure; VEDP, ventricular end-diastolic pressure; TPG, transpulmonary gradient; $P V R$, pulmonary vascular resistance; $S_{20}$, arterial oxygen saturation; $Q s$, cardiac index.

The last follow-up catheterization data are shown in Table 2. Follow-up catheterization was performed in $53.5 \%$ patients at a mean follow up of $35.7 \pm 23.3$ months. The arterial oxygen saturation $\left(\mathrm{SaO}_{2}\right)$ was significantly lower in the fenestration group than in the group without fenestration $(90.8 \% \pm$ $4.4 \%$ vs $92.6 \% \pm 4.6 \% ; P=.044)$. The other catheterization data, such as PAP, ventricular end-diastolic pressure, TPG, $\mathrm{PVR}, \mathrm{SaO}_{2}$, and cardiac index, demonstrated no statistically significant differences.

\section{Mortality and Risk Factors for Death}

The hospital mortality was 3.0\% $(\mathrm{n}=6)$ and the late mortality was $3.6 \%(\mathrm{n}=7)$ with a mean follow-up of $52.4 \pm 32.2$ months (range 18 days to 120 months) for the entire cohort. The hospital mortality rate was $4.7 \%(n=4)$ in patients with fenestration and $1.7 \%(\mathrm{n}=2)$ in those without fenestration $(P=.224)$. There were $4(4.9 \%)$ late deaths in patients with fenestration and $3(2.7 \%)$ late deaths in patients without fenestration. The 10 -year survival was $92.4 \% \pm 2.1 \%$ for the entire cohort. The 10 -year survival was $90.3 \% \pm 3.3 \%$ in patients with fenestration and $93.7 \% \pm 3.0 \%$ in patients without fenestration. There was no significant difference in survival between the two groups $(P=.21, \log$-rank test $)$ (Figure 1).

Univariate analysis indicated that a postoperative severe infection (mediastinitis) $(P=.001)$, protein-losing enteropathy (PLE) after the Fontan operation $(P=.008)$, and a high PAP during the preoperative period $(P=.003)$ were statistically significant risk factors. Multivariate analysis identified postoperative severe infection (hazard ratio $=12.439 ; P=.001$ )
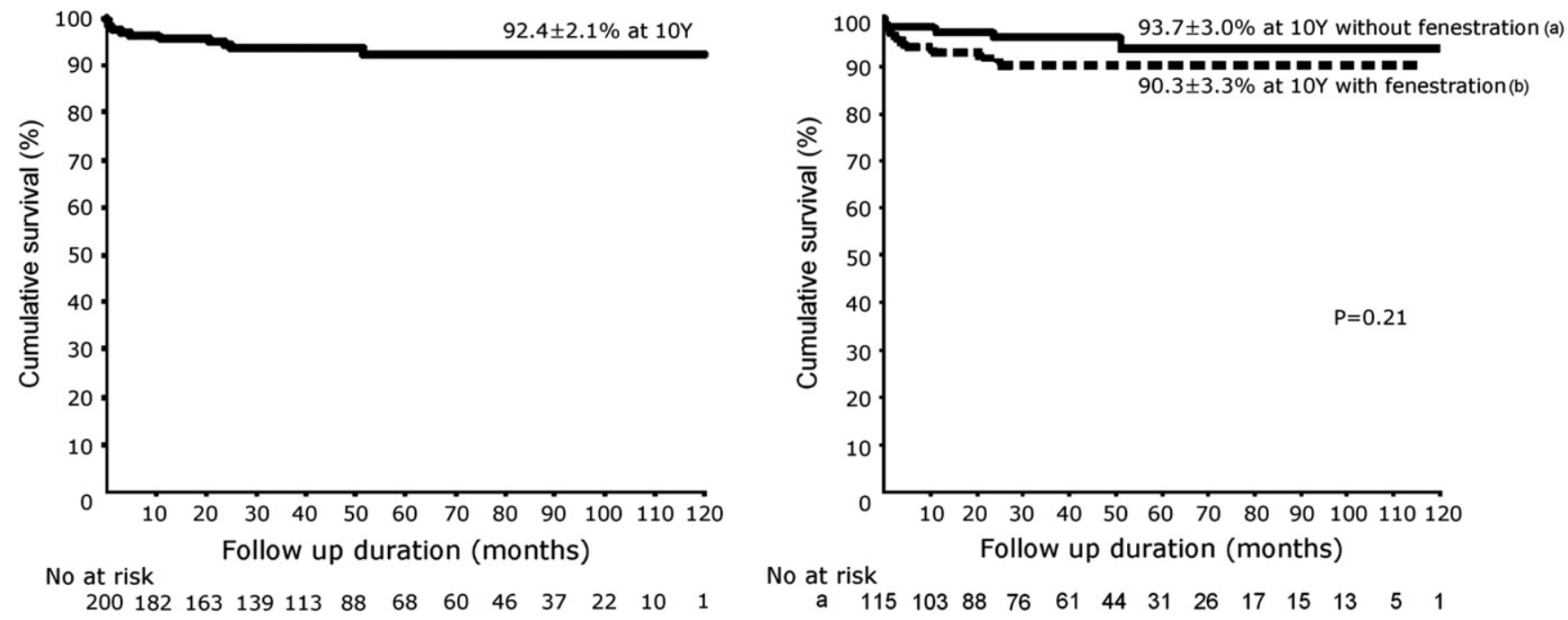

A

No at risk

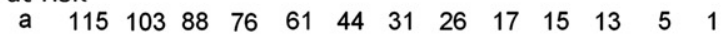

B $\quad \begin{array}{llllllllllllll}\text { b } & 85 & 79 & 75 & 63 & 52 & 44 & 37 & 34 & 29 & 22 & 9 & 5 & 0\end{array}$

Figure 1. Survival. A, Kaplan-Meier curve for the entire cohort. B, Kaplan-Meier survival curve for patients with a fenestration (dashed line) and without a fenestration (solid line).

110 The Journal of Thoracic and Cardiovascular Surgery • July 2008 
and high PAP during the preoperative period (hazard ratio $=3.445 ; P=.038$ ) as risk factors for mortality. The heterotaxy syndrome, anatomic factors, other hemodynamic data, fenestration, arrhythmia, and thrombosis were not significant risk factors for death in this study (Table 3 ).

\section{Early Postoperative Data}

Postoperative central venous pressure was significantly higher in patients with fenestration than in those without fenestration $(15.6 \pm 2.5$ vs $14.6 \pm 2.5 ; P=.008)$ and postoperative $\mathrm{SaO}_{2}$ was significantly lower in patients with fenestration than in those without fenestration $(90.6 \% \pm 5.4 \%$ vs $94.4 \% \pm 6.1 \% ; P=.001)$. The postoperative low cardiac output syndrome occurred more frequently in the fenestration group than in those patients without fenestration (7.1\% vs $1.7 \% ; P=.058)$. There was no significant difference of other postoperative hemodynamic data such as blood pressure, urine output, ventilator care, a chest tube drain, chylothorax, neurologic sequalae, infection, and respiratory failure among patients with and without fenestration.

\section{Reoperations}

Reoperation was performed in $24(12.0 \%)$ patients and the Kaplan-Meier estimate for freedom from reoperation was $82.4 \% \pm 4.1 \%$ at 10 years (Figure 2). Reoperation includes revision of a conduit $(n=7)$, revision or addition of fenestration $(n=6)$, repair of atrioventricular valve $(n=5)$, insertion of a permanent pacemaker $(n=5)$, angioplasty of a pulmonary artery $(n=4)$, takedown of the Fontan conduit and hepatic vein-azygos vein anastomosis $(\mathrm{n}=3)$, atrial septectomy, unroofing of the coronary sinus, and widening of the left ventricular outflow tract. The causes of revision of a conduit $(\mathrm{n}=7)$ were as follows: One patient had coagulopathy owing to protein $\mathrm{C}$ deficiency and needed conduit revision
TABLE 3. Risk factors for mortality

\begin{tabular}{lcccc}
\hline & & \multicolumn{3}{c}{ Multivariate } \\
\cline { 3 - 5 } \multicolumn{1}{c}{ Variables } & $\begin{array}{c}\text { Univariate } \\
\text { P value }\end{array}$ & $\boldsymbol{P}$ value & Hazard ratio & 95\% Cl \\
\hline Heterotaxy & .476 & .778 & & \\
AV valve & .678 & .282 & & \\
Ventricle type & .988 & .679 & & \\
Abnormal PVD & .369 & .327 & & \\
Preop. PAP $>$ & .003 & .038 & 3.445 & \\
$\quad 15$ mm Hg & & & & \\
Preop. VEDP $>$ & .143 & .850 & & \\
$\quad 10$ mm Hg & & & & \\
Fenestration & .132 & .113 & & \\
Postop. CVP $>$ & .351 & .914 & & \\
$\quad 15$ mm Hg & & & & \\
Infection & .001 & .001 & 12.439 \\
PLE & .006 & .301 & & \\
Arrhythmia & .171 & .689 & & \\
Thrombosis & .717 & .845 & \\
\hline
\end{tabular}

$A V$, Atrioventricular; $P V D$, peripheral vascular disease; $P A P$, pulmonary artery pressure; $V E D P$, ventricular end-diastolic pressure; $C V P$, central venous pressure; $P L E$, protein-losing enteropathy.

with removal of a large thrombus. In early series, a Hemashield conduit was used in several patients, and one of them showed early concentric stenosis of the conduit necessitating revision. One patient with heterotaxy syndrome had wide separate drainage of left hepatic veins and showed persistent cyanosis after the Fontan procedure. Revision of the conduit was needed to include the residual hepatic vein. Three other patients had low cardiac output after the Fontan operation. Two of them had mediastinitis and 1 had PLE. Thrombo-occlusion of the Fontan pathway was detected during long hospital stays even with strict anticoagulation. All 3

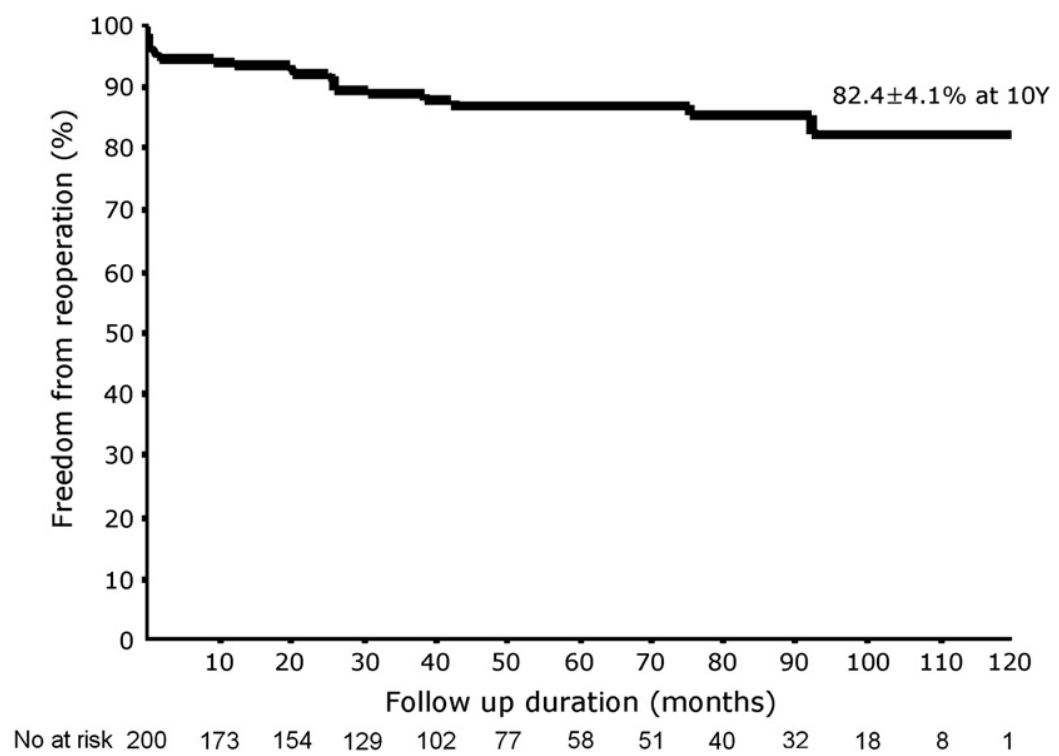

Figure 2. Kaplan-Meier curve of freedom from reoperation. 
patients had surgical removal of thrombus with conduit revision. The causes of conduit revision were assocated with post-Fontan hemodynamic state or coagulopathy.

Revision or addition of fenestration was performed more frequently in patients with fenestration (5.9\%) than in those without fenestration $(0.9 \%)$, and this difference was statistically significant $(P=.040)$. There were no significant differences with regard to reoperation between the two groups. The need for reoperation over the 10 -year period was not significantly different between the groups with and without fenestration $(88.4 \% \pm 3.6 \%$ vs $78.0 \% \pm 6.1 \% ; P=.21)$.

\section{Arrhythmia}

Arrhythmia occurred in 32 (16.0\%) patients after the Fontan operation. Bradyarrhythmia occurred in 26 patients; sinus node dysfunction developed in 22 , sinus bradycardia in 1 , and atrioventricular block in 3. A permanent pacemaker implantation was required in 12 patients. Tachyarrhythmia occurred in 10 patients; paroxysmal supraventricular tachycardia in 8 , atrial flutter in 2 , and junctional ectopic tachycardia in 1 . Fifteen $(7.5 \%)$ patients had early postoperative arrhythmias and $15(7.7 \%)$ had late postoperative arrhythmias. The Kaplan-Meier estimate of freedom from overall arrhythmia at 10 years was $79.8 \% \pm 3.7 \%$ and freedom from late arrhythmia at 10 years was $85.1 \% \pm 4.4 \%$ (Figure 3, $A$ ). Risk factors for arrhythmia included heterotaxy syndrome (hazard ratio $=3.914 ; P=.001$ ), follow-up duration (hazard ratio $=0.986 ; P=.027$ ), and age at the Fontan operation (hazard ratio $=1.151 ; P=.001$ ). The risk factor for late bradyarrhythmia was left isomerism (hazard ratio $=3.479$; $P=.038$ ).

The Kaplan-Meier estimates of freedom from tachyarrhythmia were $98.4 \% \pm 0.9 \%$ at 10 years. The Kaplan-Meier estimates of freedom from bradyarrhythmia were $88.0 \% \pm$ $3.7 \%$ at 10 years. There was a statistically significant difference in the type of late arrhythmia $(P=.007)$ (Figure 3, $B)$. The Kaplan-Meier estimate of freedom from late arrhythmia at 10 years was $74.9 \% \pm 8.9 \%$ and of freedom from late bradyarrhythmia was $66.9 \% \pm 16.5 \%$ at 10 years in heterotaxy. The patients with heterotaxy had a higher incidence of late arrhythmia and late bradyarrhythmia than nonheterotaxy patients $(P=.015$ and $P=.007$, respectively) (Figure 3, $C$ and $3, D)$.

\section{Thromboembolism}

Thromboembolism occurred in $13(6.5 \%)$ patients. The Kaplan-Meier estimate of freedom from thromboembolism was $92.9 \% \pm 1.9 \%$ at 10 years (Figure 4). Most patients $(11 / 13,84.6 \%)$ who had a thromboembolism sustained the complication within 1 year after the Fontan procedure. Six of these patients underwent surgical management (Table 4). Among the 13 patients who had a thromboembolism, 1 (7.69\%) patient died; among the 187 patients without a thromboembolism, $12(6.42 \%)$ died. There was no statistically sig- nificant difference in mortality according to the occurrence of thromboembolism $(P=.86)$.

\section{Other Complications and Follow-up}

PLE was observed in 5 patients. PLE occurred more frequently in the fenestration group than in those without fenestration $(4.7 \%$ vs $0.9 \% ; P=.086)$, although this difference did not reach statistical significance. Two patients died and 3 patients improved after medical treatment with heparin or/and supportive management. Four patients who had left isomerism had a persistent pulmonary arteriovenous malformation even after Fontan completion and required reoperation to provide an even distribution of hepatic blood flow to both lungs. There were $25.4 \%$ (50/197) who showed systemic ventricular dysfunction and $11.1 \%(22 / 198)$ who had atrioventricular regurgitation of more than a moderate degree with a mean follow-up duration of $37.7 \pm 30.2$ months $(0.2$ 108.3 months).

Follow-up information on the functional status and medication were available for 187 patients $(93.5 \%), 95.2 \%(\mathrm{n}=$ 178) met the criteria for the New York Heart Association functional class I, and 4.8\% ( $\mathrm{n}=9)$ met the criteria for functional class II. Anticoagulation was provided with aspirin in 170 patients (90.9\%) and with warfarin sodium (Coumadin) in $17(9.1 \%)$. Cardiovascular medication was provided in 87 $(46.5 \%)$ patients and antiarrhythmic medication in $2(1.1 \%)$. There was no statistically significant difference in functional class and medication between the patients with fenestration and those without fenestration.

\section{Extracardiac Conduit and Fenestration}

Recently, $\mathrm{we}^{3}$ reported the change in status of polytetrafluoroethylene grafts used in the extracardiac conduit Fontan procedure. In 48 patients who underwent follow-up catheterization, the internal diameter of the conduit and inferior vena cava were measured angiographically. The mean conduitinferior vena cava cross-sectional area was $1.25 \pm 0.33$. The mean percent decrease of the conduit cross-sectional area was $14.3 \% \pm 8.5 \%$ with a mean follow-up duration of $36.1 \pm 19.7$ months. Follow-up duration and the percent decrease of the conduit cross-sectional area did not show a significant correlation $(r=0.22 ; P=.14)$. Among the 34 patients who underwent a fenestrated Fontan operation and follow-up catheterization later, 74\% $(\mathrm{n}=25)$ showed a spontaneous closure of the fenestration after a median of 25 months (range 4-67 months). All patients who had a 3.5-mm fenestration had it close spontaneously and none with a 6-mm fenestration had spontaneous closure. Most fenestrations closed spontaneously within 22 months after the Fontan operation.

\section{Discussion}

Since the introduction of the total cavopulmonary anastomosis by Fontan and Baudet ${ }^{4}$ more than 30 years ago, modifications 

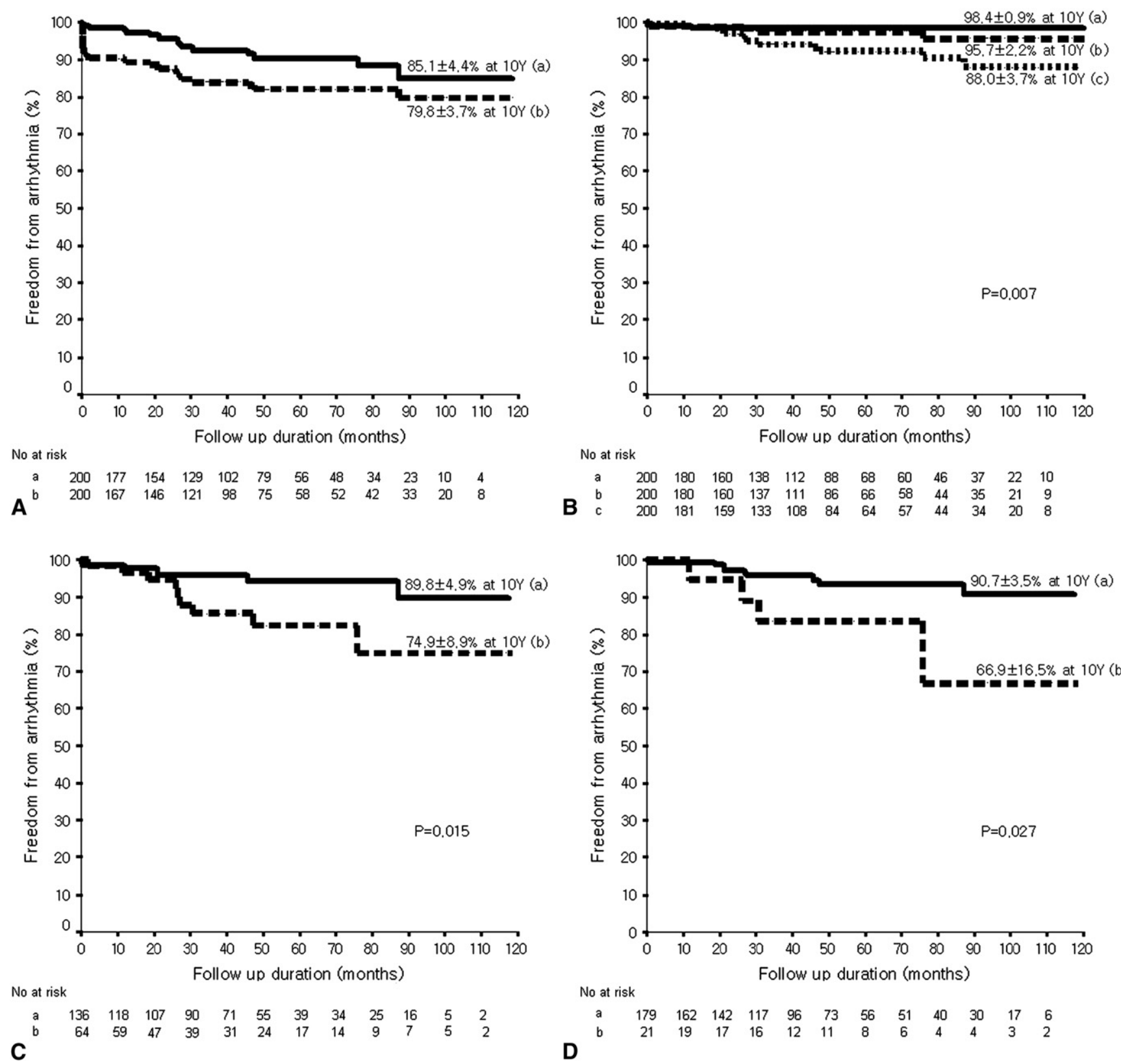

Figure 3. Kaplan-Meier curve of freedom from arrhythmia. A, Kaplan-Meier curve of freedom from overall arrhythmias (b, dashed line) and freedom from late arrhythmias (a, solid line). B, According to the type of late arrhythmia, the Kaplan-Meier curve for tachyarrhythmias (a, solid line), for bradyarrhythmias (c, thin dashed line), and for a permanent pacemaker (b, thick dashed line) are shown. C, Kaplan-Meier curve for late arrhythmias in patients with heterotaxy syndrome (dashed line) and without heterotaxy syndrome (solid line). D, Kaplan-Meier curve for late bradyarrhythmias in patients with heterotaxy syndrome (dashed line) and without heterotaxy syndrome (solid line).

of the Fontan procedure and staging with BCPS have extended the indications for this operation, which is now applied to a wide range of congenital heart defects unsuitable for biventricular repair. ${ }^{5,6}$ Furthermore, the creation of fenestration in the Fontan pathway reduces early mortality and morbidity even in patents for whom the risk of Fontan completion is high. ${ }^{7}$ Despite the improvements in surgical techniques that have reduced the perioperative mortality, ${ }^{8-10}$ late deterioration in functional status has been observed with a longer duration of follow-up. ${ }^{11-13}$

The significant evolution of the Fontan procedure has been associated with improvements in early mortality from 


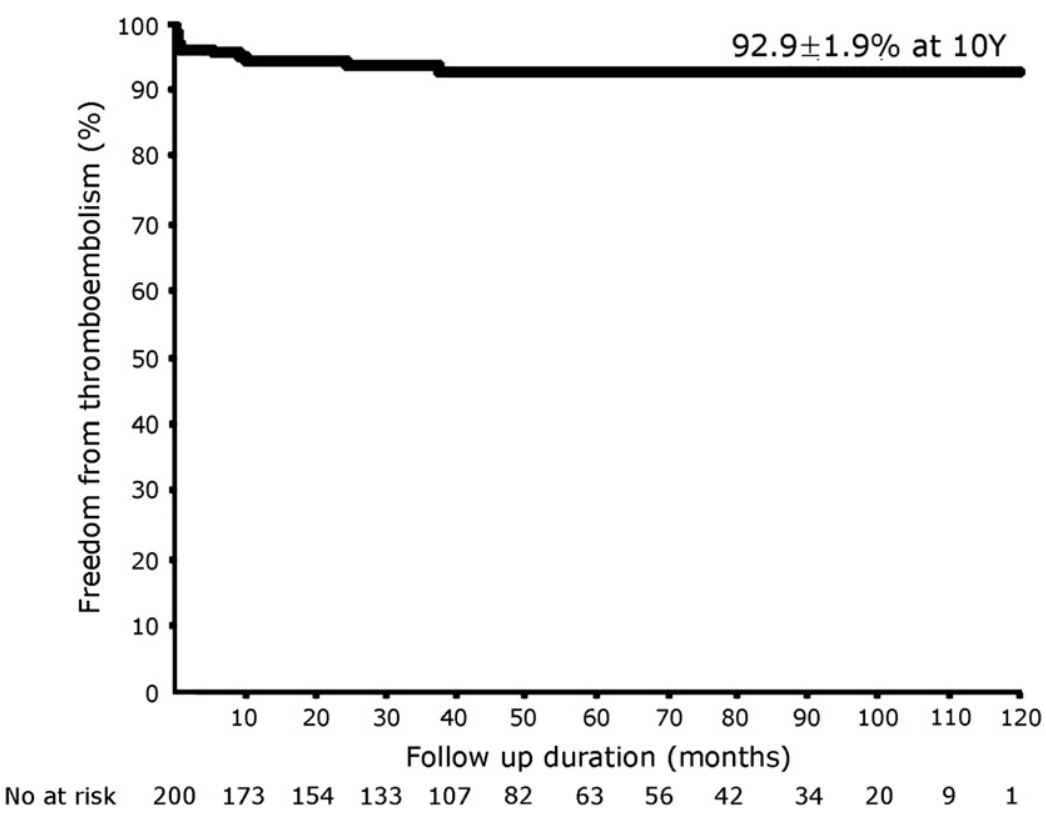

Figure 4. Kaplan-Meier curve of freedom from thromboembolism.

$20 \%$ to $40 \%$ in the late 1970 s to below $6.6 \%$ currently. ${ }^{14}$ In earlier studies, midterm and long-tem survival revealed the potentially finite life span of a Fontan circulation, with the overall 1-, 5-, and 10-year survivals found to be $77 \%, 70 \%$, and $60 \%$, respectively, in the Mayo Clinic study ${ }^{15}$ Followup also often suggested a poor functional capacity. At 5 years, only $26 \%$ of patients were free from significant cardiac symptoms. ${ }^{16}$ Similarly, the early mortality rate was low $(3.3 \%)$ in this study, despite the presence of heterotaxy, known to be a high risk factor for the Fontan operation; our study population included many patients with the heterotaxy syndrome $(32 \%, \mathrm{n}=64)$. However, consistent with the findings of others, we have demonstrated an improved late outcome with a 10 -year survival of $92.4 \% \pm 2.1 \% .{ }^{17}$ The majority of these patients at a median follow-up of 6 years

\section{TABLE 4. Thromboembolism}

\begin{tabular}{cc}
\hline Type of thromboembolism & No. \\
\hline Surgical management & 6 \\
Conduit thrombosis & 5 \\
Conduit change & 3 \\
Left HV to PA & 1 \\
Conduit thrombectomy & 1 \\
PV thrombosis & 1 \\
Medical management & 7 \\
Cerebral infarction & 3 \\
Conduit thrombosis & 2 \\
IVC thrombosis & 1 \\
LPA thrombosis & 1 \\
\hline
\end{tabular}

$H V$, Hepatic vein; $P A$, pulmonary artery; $P V$, pulmonary vein; $I V C$, inferior vena cava; $L P A$, left pulmonary artery. were in New York Heart Association functional class I or II $(95.2 \%$ vs $4.8 \%)$.

Medical therapy such as angiotensin-converting enzyme inhibitors and the long-term benefits of anticoagulation may have contributed to the improved long-term outcome of these patients. Our policy is to maintain all patients on low-dose aspirin, except for high-risk patients. In addition, angiotensin-converting enzyme inhibitors are used in patients with evidence of impaired ventricular function or atrioventricular valve regurgitation.

Late morbidity commonly includes pathway obstruction, ${ }^{18}$ atrial arrhythmia, ${ }^{19-21}$ cyanosis because of systemic venous collateralization, ${ }^{22}$ thrombus formation, ${ }^{23}$ PLE, ${ }^{24}$ and pulmonary arteriovenous malformation. ${ }^{25,26}$ In comparison with other modifications of the Fontan operation, the reoperation rate resulting from pathway obstruction or cyanosis from right-to-left shunting as well as tachyarrhythmias was very low. These low rates are thought to be among the advantages associated with the extracardiac modification. In this study, despite the use of the extracardiac conduit and anticoagulation with aspirin, the incidence of thromboembolism was not more than in previous reports. This may suggest that the thromboembolism risk is more closely associated with suboptimal hemodynamics or an underlying coagulopathy than the conduit itself. The conduit cross-sectional area decreased by $14 \%$, and this did not differ according to the conduit size used. The extent of decrease of the conduit cross-sectional area remained stable regardless of the follow-up duration. However, longer follow-up is needed to determine the development of stenosis as the patients grow. Considering the high incidence of heterotaxy syndrome $(32 \%)$, the incidence of early and late postoperative 
arrhythmia was relatively low and, in particular, the incidence of tachyarrhythmia was rare in our study population. The incidence of tachyarrhythmia during follow-up was rare. The only risk factor for bradyarrhythmia during follow-up was left isomerism. This suggests that the extracardiac Fontan modification reduces the incidence of postoperative arrhythmia, as reported by a previous study. ${ }^{27}$

There is much debate regarding the pros and cons of the Fontan circuit fenestration. Some studies have found that the fenestrations significantly reduce the duration of postoperative effusions, length of time in the hospital, and in some centers early mortality. ${ }^{10,28}$ The disadvantages of the fenestrations have been reported to be the ongoing risk for a paradoxical embolus, persistent cyanosis, and an increased incidence of late catheter intervention for device closure of the fenestration. Therefore, the overall benefit of routine fenestration in Fontan patients remains uncertain. ${ }^{29}$ In this study, the high-risk patients required fenestration during the Fontan operation with high PAP, TPG, and PVR preoperatively. It is interesting that they showed good hemodynamic parameters similar to those of patients who were not considered at high risk postoperatively. In addition, the early outcome of the high-risk group was comparable with that of the groups considered not to be at a high risk (early mortality $4.7 \%$ vs $1.7 \%$; $P=.224)$. Fortunately, catheter reintervention after the Fontan procedure was infrequent because the spontaneous closure rate of the fenestration was high (74\%) without the subsequent need for fenestration, and residual right-to-left shunt leak was infrequent. However, because of the beneficial long-term effects of fenestration, the need for permanent fenestration should be considered at least for some patients despite the risk of thromboembolism.

\section{Conclusions}

After 10 years of follow-up, the overall survival and the functional status of survivors after the extracardiac Fontan procedure were satisfactory. We might infer that fenestration provided benefit because the Fontan patients undergoing fenestration, who were at high risk, had similar outcomes to those not fenestrated, who were presumably at low risk. To clarify this, a large prospective randomized study is needed. The incidence of late deaths, reoperations, obstructions of the cavopulmonary pathway, arrhythmias, and thromboembolism was low.

\section{References}

1. Marcelletti C, Iorio FS, Abella RF. Late results of extracardiac Fontan repair. Semin Thorac Cardiovasc Surg Pediatr Card Surg Annu. 1999;2:131-42.

2. Azakie A, McCrindle BW, Van Arsdell G, Benson LN, Coles G, Hamiton R, et al. Extracardiac conduit versus lateral tunnel cavopulmonary connections at a single institution: impact on outcomes. $J$ Thorac Cardiovasc Surg. 2001;122:1219-28.

3. Lee C, Lee CH, Hwang SW, Lim HG, Kim SJ, Lee JY, et al. Midterm follow-up of the status of Gore-Tex graft after extracardiac conduit Fontan procedure. Eur J Cardiothorac Surg. 2007;31:1008-12.
4. Fontan F, Baudet E. Surgical repair of tricuspid atresia. Thorax. 1971; 26:240-8.

5. de Leval MR, Kilner P, Gewillig M, Bull C. Total cavopulmonary connection: a logical alternative to atriopulmonary connection for complex Fontan operations. Experimental studies and early clinical experience. J Thorac Cardiovasc Surg. 1988;96:682-95.

6. Bridges ND, Jonas RA, Mayer JE, Flanagan MF, Keane JF, Castaneda AR. Bidirectional cavopulmonary anastomosis as interim palliation for high-risk Fontan candidates. Early results. Circulation. 1990; 82(5 Suppl):IV170-6.

7. Bridges ND, Lock JE, Castaneda AR. Baffle fenestration with subsequent transcatheter closure. Modification of the Fontan operation for patients at increased risk. Circulation. 1990;82:1681-9.

8. Kaulitz R, Ziemer G, Luhmer I, Kallfelz HC. Modified Fontan operation in functionally univentricular hearts: preoperative risk factors and intermediate results. J Thorac Cardiovasc Surg. 1996;112:658-64.

9. Gentles TL, Mayer JE Jr, Gauvreau K, Newburger JW, Lock JE, Kupferschmid JP, et al. Fontan operation in five hundred consecutive patients: factors influencing early and late outcome. J Thorac Cardiovasc Surg. 1997;114:376-91.

10. Lemler MS, Scott WA, Leonard SR, Stromberg D, Ramaciotti C. Fenestration improves clinical outcome of the Fontan procedure: a prospective, randomized study. Circulation. 2002;105:207-12.

11. Fontan F, Kirklin JW, Fernandez G, Costa F, Naftel DC, Tritto F, et al. Outcome after a "perfect" Fontan operation. Circulation. 1990;81: 1520-36.

12. Gentles TL, Gauvreau K, Mayer JE Jr, Fishberger SB, Burnett J, Colan SD, et al. Functional outcome after the Fontan operation: factors influencing late morbidity. J Thorac Cardiovasc Surg. 1997;1 14:392-403.

13. Alphonso N, Baghai M, Sundar P, Tulloh R, Austin C, Anderson D. Intermediate-term outcome following the Fontan operation: a survival, functional and risk-factor analysis. Eur J Cardiothorac Surg. 2005;28: 529-35.

14. Mitchell ME, Ittenbach RF, Gaynor JW, Wernovsky G, Nicolson S, Spray TL. Intermediate outcomes after the Fontan procedure in the current era. J Thorac Cardiovasc Surg. 2006;131:172-80.

15. Cetta F, Feldt RH, O'Leary PW, Mair DD, Warnes CA, Driscoll DJ, et al. Improved early mortality and morbidity after Fontan operation: The Mayo Clinic experience, 1987 to 1992. J Am Coll Cardiol. 1996;28:480-6.

16. Driscoll DJ, Offord KP, Feldt RH, Schaff HV, Puga FJ, Danielson GK. Five- to fifteen-year follow-up after Fontan operation. Circulation. 1992;85:469-96.

17. Kim SJ, Kim WH, Lim HG, Lee CH, Lee JY. Improving results of Fontan procedure in patients with heterotaxy syndrome. Ann Thorac Surg. 2006;82:1245-51.

18. Petko M, Myung RJ, Wernovsky G, Cohen MI, Rychik J, Nicolson SC. Surgical reinterventions following the Fontan procedure. Eur J Cardiothorac Surg. 2003;24:255-9.

19. Fishberger SB, Wernovsky G, Gentles TL, Gauvreau K, Burnett J, Mayer JE Jr, et al. Factors that influence the development of atrial flutter after the Fontan operation. J Thorac Cardiovasc Surg. 1997; 113:80-6.

20. Durongpisitkul K, Porter CJ, Cetta F, Offord KP, Slezak JM, Puga FJ, et al. Predictors of early- and late-onset supraventricular tachyarrhythmias after Fontan operation. Circulation. 1998;98:1099-107.

21. Weipert J, Noebauer C, Schreiber C, Kostolnv M, Zrenner B, Wacker A, et al. Occurrence and management of atrial arrhythmia after long-term Fontan circulation. J Thorac Cardiovasc Surg. 2004;127:457-64.

22. Kaulitz R, Ziemer G, Paul T, Peuster M, Bertram H, Hausdorf G. Fontan-type procedures: residual lesions and late interventions. Ann Thorac Surg. 2002;74:778-85.

23. Kaulitz R, Ziemer G, Rauch R, Girsch M, Bertram H, Wessel A, et al. Prophylaxis of thromboembolic complications after the Fontan operation (total cavopulmonary anastomosis). J Thorac Cardiovasc Surg. 2005;129:569-75.

24. Mertens L, Hagler DJ, Sauer U, Somerville J, Gewillig M. Proteinlosing enteropathy after the Fontan operation: an international multicenter study. PLE study group. J Thorac Cardiovasc Surg. 1998;115: 1063-73.

25. Kawashima Y. Cavopulmonary shunt and pulmonary arteriovenous malformations. Ann Thorac Surg. 1997;63:930-2. 
26. Kim SJ, Bae EJ, Cho DJ, Park IS, Kim YM, Kim WH, et al. Development of pulmonary arteriovenous fistulas after bidirectional cavopulmonary shunt. Ann Thorac Surg. 2000;70:1918-22.

27. Bae EJ, Lee JY, Noh CI, Kim WH, Kim YJ. Sinus node dysfunction after Fontan modifications-influence of surgical method. Int $J$ Cardiol. 2003;88:285-91.
28. Airan B, Sharma R, Choudhary SK, Mohanty SR, Bhan A, Cowdhari UK, et al. Univentricular repair: is routine fenestration justified? Ann Thorac Surg. 2000;69:1900-6.

29. Thompson LD, Petrossian E, McElhinney DB, Abrikosova NA, Moore P, Reddy VM, et al. Is it necessary to routinely fenestrate an extracardiac fontan? J Am Coll Cardiol. 1999;34:539-44.

Access to The Journal of Thoracic and Cardiovascular Surgery Online is reserved for print subscribers!

Full-text access to The Journal of Thoracic and Cardiovascular Surgery Online is available for all print subscribers. To activate your individual online subscription, please visit The Journal of Thoracic and Cardiovascular Surgery Online, point your browser to http://www.mosby.com/jtcvs, follow the prompts to activate your online access, and follow the instructions. To activate your account, you will need your subscriber account number, which you can find on your mailing label (note: the number of digits in your subscriber account number varies from 6 to 10). See the example below in which the subscriber account number has been circled:

\section{Sample mailing label}

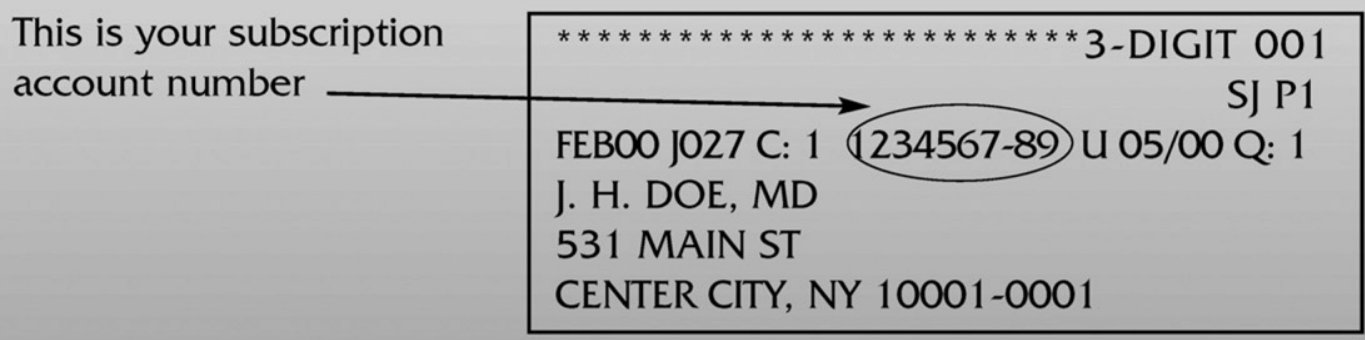

Personal subscriptions to The Journal of Thoracic and Cardiovascular Surgery Online are for individual use only and may not be transferred. Use of The Journal of Thoracic and Cardiovascular Surgery Online is subject to agreement to the terms and conditions as indicated online. 